Original article

\title{
The Role of Ultrasound in Evaluation of Antenatal Complications Related to Previous Cesarean Section
}

\author{
Hesham E. El sheikh, Shorouk Z. Abdelshafy, Hend F. El Welily
}

\begin{abstract}
Department of Radio diagnosis and Medical Imaging, Faculty of Medicine Benha University, Egypt.
\end{abstract}

Correspondence to: Hend F. El Welily, Department of Radio diagnosis and Medical Imaging, Faculty of Medicine Benha University, Egypt.

\section{Email:}

fouaddodo92@gmail.com

Received: 21 November 2020

Accepted: 1 September 2021

\begin{abstract}
Background: Pregnant females with prior Cesarean section (CS) are at risk of multiple complications that depend on the number of previous CS. Problems of placenta are the most common complications related to previous CS. Ultrasound (US) is requested for routine screening obstetric examination in all patients. Purpose: The aim of the study is to highlight the risks of repeated CS on the future pregnancy and the severity of elective CS, hoping to decrease this trend specially if not indicated. Also, to show the helpful role of US in detection of these complications during antenatal period.
\end{abstract} Materials and methods: This retrospective study included 100 pregnant females. Patients attended for sonographic examination at the radiology department of Belbeis general hospital with history of previous CS during the period between December 2018 till February 2020. All patients were scanned by US. Results: 51 patients proved to have complications related to previous CS and diagnosed by US. The complications included Placenta Previa (PP), Intra uterine growth restriction (IUGR), Oligohydramnios, breech presentation and preterm labor. Placental problems were the commonest complication discovered in patients with repeated CS. Conclusion: Repeated CS is a risk factor for multiple complications expected to occur in the new pregnancy and US is accurate in detecting these complications.

Key words: Complications- Pregnancy-Repeated Cesarean section- Ultrasound Abbreviations: CS- CSEP- IUGR- P.P- TVUS- UR- US. 


\section{Introduction:}

Cesarean delivery is the most common major abdominal operation done in Obstetrics and Gynecology departments. Although CS is a life-saving surgical procedure in some cases, it is a risk factor for today and future complications expected in the future new pregnancy. The risk of these complications depends on the increased number of previous CS done (1). Complications include risk for occurrences of placenta previa (P.P), ectopic pregnancy on the CS scar (CSEP) and uterine rupture (UR) (2).

Problems of placenta are the most common complications related to previous CS in the second trimester (3). The more CS patient had, the greater is the risk of developing problems with the placenta (4). The placenta may implant too deeply into the uterine wall (placenta accreta) or partially or completely covering the opening of the cervix (P.P) (3). Intra uterine growth restriction (IUGR) is another complication during the second trimester specially if associated with other placental abnormalities (5).

Uterine rupture (UR) is reported with increased number of previous CS (4). Cesarean section ectopic pregnancy (CSEP) is the complication related to previous $\mathrm{CS}$ at the first trimester. It was a rare complication but nowadays, it became more common (6). It is an increasingly reported complication requiring a high degree of suspicion for the diagnosis because, early diagnosis (1st trimester) decrease the risk of hysterectomy and improve the prognosis. The prevalence is about 1:1800 pregnancies (7).

Severe oligohydramnios with subsequent preterm labor is a cause of induced CS at third trimester (8).

Ultrasound (US) is the most widely used medical imaging modality for viewing the fetus during pregnancy. Routine examinations are planned for early pregnancy, late gestation, or both to assess and monitor the health status of both fetus and mother (9).

The US scan could be requested for many reasons in obstetrics. It is ideal to look at the fetus and how he grows throughout the stages of pregnancy and to exclude presence of complications with the pregnancy as early detection of these complications will help the obstetrician to interfere at the proper time to have better prognosis with lesser losses (10).

Transvaginal ultrasound (TVUS) in the first trimester of pregnancy permits the extremely detailed observation of pregnancy (11). It is also used to confirm an 
intrauterine pregnancy, establishing accurate dating, and is crucial in diagnosing early pregnancy failure and ectopic pregnancy (12).

During the second and third trimesters, US is used to evaluate fetal growth, examine fetal wellbeing to ensure the fetus is growing in a healthy manner, estimate the amniotic fluid volume and examine the placenta (13).

\section{Purpose}

The aim of this study was to assess the role of US in evaluation of the antenatal complications that are in relation with previous CS.

\section{Subjects and methods}

This is a retrospective study included one hundred pregnant females attending for sonographic examination at the radiology department of Belbeis general hospital with history of previous CS during the period between December 2018 till February 2020. An approval of local research ethical committee of Benha faculty of medicine was taken.

Out of the one hundred patients, forty-nine patients showed absence of complications related to previous $\mathrm{CS}$ and were excluded from the study while, the remaining fiftyone patients proved to have complications related to previous CS and were included in our study.

\section{Inclusion criteria:}

All pregnant females with history of previous CS and found to have complications related to previous CS with sonographic examination.

These patients approved to participate in our study.

\section{Exclusion criteria:}

Any patient that underwent sonographic examination and showed absence of complications related to previous CS.

Patients refused to participate in our study.

\section{Methods:}

\section{All patients were subjected to the} following

- Complete clinical history taking

- US examination included transabdominal US for patients at the second and third trimester (50 patients). Other patients in the first trimester underwent combined trans abdominal and transvaginal US (1 patient).

\section{Technique:}

\section{Transabdominal US:}

Done in the second and third trimester. 
The patients were examined in supine position using convex probe

\section{The following parameters were recorded.}

- Fetal biometry including measurement of BPD, FL and AC to assess GA and FBW.

- Assessment of placenta including its site, grading, distance from the internal os, placental thickness, the presence of retro placental collection or hematomas and assessment of RPS.

- Liquor: The amount of liquor was assessed by using AFI in all patients.

- Fetal examination including the presence of fetal congenital anomalies, its viability, presentation and lie.

\section{Doppler examination:}

- For the feto-placental circulation.

- Doppler study was done for one patient with suspected IUGR based on clinical examination and morphological findings of US (GA, advanced Placental grading and amount of liquor).

- For one patient with suspected placenta accreta based on US findings (absent RPS, thin myometrium and irregular retroplacental vessels).
- For patients with suspected oligohydramnios (16 patient).

- For confirmation of fetal viability in all cases.

\section{The following parameters were recorded} and calculated from results:

PSV, RI and PI Doppler indices for the UA, MCA and both uterine arteries.

\section{Transvaginal US:}

The patient was examined in lithotomy position using transvaginal probe with proper evacuation of UB before the exam. The probe was introduced within the vagina and the female was examined for cervical canal length assessment, site of the placenta and its distance from the internal os.

TVUS was performed for only for 1 patient with suspected low lie placenta.

No patients found with suspected CSEP to be assessed during the study.

\section{Statistical analysis}

The collected data were revised, coded, tabulated and introduced to pc using the software SPSS statistics for windows, (Statistical Package for the Social Sciences) version 20.0. Armonk, NY: IBM Corp. Quantitative variables were described using their means and standard deviations. Categorical variables were described using 
their absolute frequencies and were compared using Chi square test and fisher exact test when appropriate.

Sensitivity was calculated by number of true positive detected by US/True positive as detected intraoperatively*100. Specificity $=$ number of true negative detected by US/True negative as detected intraoperatively*100. PPV $=$ true positive by US/all positive by $\mathrm{US}^{*} 100$. NPV $=$ true positive by US/all positive by US* 100 . Accuracy $=$ (true positive by US+ true negative by US)/100. The level statistical significance was set at 5\% $(P<0.05)$. Highly significant difference was present if $p \leq 0.001$

\section{Results:}

The Sonographic findings and doppler findings results were correlated with final diagnosis based on intrapartum findings which proved the accuracy of US findings as the following, The accuracy of US findings were $100 \%$ accuracy in fetal malpositioning (Transverse lie position), 98\% accuracy in breech position, 98\% accuracy in UR, 96.1\% accuracy in abnormal placental site, 94.1\% accuracy in PP accreta, 96.1\% accuracy in IUGR, 90.2\% accuracy in abnormally low AFI and $80.4 \%$ accuracy in preterm labor.
Univariate Odds ratio of number of CS in the developing obstetric complications Table (1).

History of 2 to $3 \mathrm{CS}$ or $4-5 \mathrm{CS}$ were protective factors against developing breech presentation in subsequent pregnancy $(\mathrm{OR}=0.6,0.267 . \mathrm{p}>0.05)$ respectively

History of 4 to 5 CS significantly increased risk of transverse lie by 14 folds $(O R=14$, $\mathrm{p}<0.05)$.

History of 2 to $3 \mathrm{CS}$ or $4-5$ CS nonsignificantly increased risk of rupture uterus by 1.53 and 1.64 folds respectively $(\mathrm{p}>0.05)$.

History of 4 -5 CS significantly increased risk of placenta accrete by about 17 folds $(\mathrm{OR}=17.1, \mathrm{p}>0.05)$.

History of previous $1 \mathrm{CS}$ increased risk of low lie placenta by about 1-fold (OR 1.06, p>0.05) while history of 2-3 previous CS increased risk of $\mathrm{P}$ marginalis by 8 folds. History of previous $4-5$ CS significantly increased risk of $\mathrm{P}$ centralis by 25.2 folds $(\mathrm{p}<0.05)$.

History of 2 to $3 \mathrm{CS}$ or 4 -5 CS were nonsignificant protective factors against developing abnormally low AFI in subsequent pregnancy $(\mathrm{OR}=0.95,0.11$, $\mathrm{p}>0.05)$ respectively.

History of 2 to $3 \mathrm{CS}$ or $4-5 \mathrm{CS}$ were risk factors for developing preterm labor in 
subsequent pregnancy by about 1 and 2 folds $\quad(\mathrm{OR}=1.1, \quad$ and $1.69, \quad \mathrm{p}>0.05)$ respectively.

History of 4 to 5 CS non-significantly increased risk of IUGR by about 2 folds $(\mathrm{OR}=1.67, \mathrm{p}>0.05)$.

The most common complication related to previous CS was abnormal placental site represented by twenty-six patients (51\%).
Thirteen $(25.5 \%)$ of these patients had low lie placenta, nine patients $(17.6 \%)$ had placenta previa marginalis and four $(7.9 \%)$ of them had placenta previa centralis. While the least common complications were UR, IUGR and PP accreta represented by one patient for each complication with percentage $=2 \%$ (Table 2 ).

Table (1) Univariate Odds ratio of number of CS in developing obstetric complications:

\begin{tabular}{|c|c|c|c|c|}
\hline Number of CS & Odds ratio & $\begin{array}{l}95 \% \text { CI } \\
\text { Lower }\end{array}$ & Upper & $\mathrm{P}$ \\
\hline \multicolumn{5}{|l|}{ Breech presentation (yes) } \\
\hline \multicolumn{5}{|l|}{1} \\
\hline 2-3 in breech presentation (yes) & 0.6 & 0.46 & 6.23 & 0.448 \\
\hline 4-5 in breech presentation (yes) & 0.267 & 0.03 & 2.38 & 0.236 \\
\hline \multicolumn{5}{|l|}{ Transverse lie (yes): } \\
\hline \multicolumn{5}{|l|}{1} \\
\hline $2-3$ & 0.153 & 0.01 & 3.99 & 0.259 \\
\hline $4-5$ & 14 & 1.09 & 179.01 & $0.04 *$ \\
\hline \multicolumn{5}{|l|}{ Rupture uterus (yes): } \\
\hline \multicolumn{5}{|l|}{1} \\
\hline $2-3$ & 1.53 & 0.06 & 39.86 & 0.8 \\
\hline $4-5$ & 1.67 & 0.06 & 44.48 & 0.761 \\
\hline \multicolumn{5}{|l|}{ Placenta accrete (yes): } \\
\hline \multicolumn{5}{|l|}{1} \\
\hline $2-3$ & 0.49 & 0.01 & 26.05 & 0.726 \\
\hline 4-5 & 17.4 & 0.64 & 468.54 & 0.089 \\
\hline \multicolumn{5}{|l|}{ Placenta site (yes): } \\
\hline 1 in producing low lie placenta & 1.06 & 0.31 & 3.61 & 0.931 \\
\hline $2-3$ in producing $p$ marginalis & 8 & 0.92 & 69.72 & 0.06 \\
\hline 4-5 in producing $p$ centralis & 25.2 & 2.18 & 290.8 & $0.01 *$ \\
\hline \multicolumn{5}{|l|}{ Abnormal low AFI (yes): } \\
\hline \multicolumn{5}{|l|}{1} \\
\hline $2-3$ & 0.95 & 0.25 & 3.6 & 0.937 \\
\hline 4-5 & 0.11 & 0.01 & 2.01 & 0.135 \\
\hline \multicolumn{5}{|l|}{ Preterm labor (yes): } \\
\hline \multicolumn{5}{|l|}{1} \\
\hline $2-3$ & 1.1 & 0.29 & 4.14 & 0.888 \\
\hline $4-5$ & 1.69 & 0.37 & 7.7 & 0.499 \\
\hline \multicolumn{5}{|l|}{ IUGR (yes): } \\
\hline \multicolumn{5}{|l|}{1} \\
\hline 2-3 & 0.153 & 0.01 & 3.99 & \\
\hline $4-5$ & 1.67 & 0.06 & 44.48 & 0.761 \\
\hline
\end{tabular}


Benha medical journal, vol. 39, special issue (radiology), 2022

Table (2) Distribution of the studied patients according to obstetric complications:

\begin{tabular}{lll}
\hline Complications & $\mathrm{N}=51$ & $\%$ \\
\hline Breech presentation: & 35 & 68.6 \\
No & 16 & 31.4 \\
Yes & & \\
IUGR: & 50 & 98 \\
No & 1 & 2 \\
Yes & & \\
Transverse lie: & 48 & 94.1 \\
No & 3 & 5.9 \\
Yes & & \\
Preterm labor: & 31 & 60.8 \\
No & 20 & 39.2 \\
Yes & & \\
Rupture uterus: & 50 & 98 \\
No & 1 & 2 \\
Yes & & \\
Abnormal placenta site: & 25 & 49 \\
No & 13 & 25.5 \\
Low lie placenta & 9 & 17.6 \\
Placenta previa marginalis & 4 & 7.9 \\
Placenta previa centralis & & \\
Placenta accreta: & 50 & 98 \\
No & 1 & 2 \\
Yes & & 70.6 \\
Amniotic fluid index: & 36 & 25.5 \\
Normal & 13 & \\
Oligohydramnios & 2 & \\
Anhydramnios & & \\
\hline
\end{tabular}

\section{Discussion}

This study with the help of US device showed that problems of placenta are the commonest complication discovered in patients with repeated CS. This agreed with Parvin et al (14) who stated that PP and PP accreta are more commonly found after previous CS and also agreed with Umbeli et al (15) in the point that women with a history of CS are at about 2- to 5-fold greater risk of PP.
Study done by Kulas et al (16) stated that the risk of PP centralis and PP accreta is increasing with the increasing number of previous CS. This agreed with our study results as three from the four patients with PP centralis in our study had more than 3 previous CS.

Sensitivity of US in diagnosis of abnormal placenta site was $96.2 \%$, and accuracy was 96.1 which was in agreement 
with Rac MW et al (17) stated that US has a good sensitivity for prenatal diagnosis of placental problems.

The Sensitivity of US and Doppler in diagnosis of IUGR was $100 \%$, and accuracy was $96.1 \%$ that agreed with Bano et al (18) who stated that Doppler US has great usefulness and accuracy in the diagnosis of IUGR and enables a better understanding of the hemodynamic changes and has therefore become one of the most important clinical tools for feto-maternal surveillance in highrisk pregnancies.

All patients suspected by US to have fetuses with transverse lie are confirmed intraoperatively with US Sensitivity equals $100 \%$, and accuracy equals $100 \%$. Our study results agreed with Oyinloye \& Okoyomo (19) who studied the abilities of US in longitudinal evaluation of fetal transverse lie and stated that US has a great accuracy in diagnosis of fetal malpositioning especially in longitudinal transverse lie.

The study results revealed that, there is statistically significant relation between number of previous CS and transverse lie as transverse lie is more significantly prevalent in patients with previous 4 to $5 \mathrm{CS}$ (two from three confirmed patients). This agreed with Betrán et al. (1) study as they stated that pregnant females with prior CS delivery are at risk of multiple complications that depend on the number of the previous CS done.

The results showed non-significant relation between breech presentation and the number of previous CS (only one patient from confirmed 16 patients with breech presentation had previous 4-5 CS) which disagreed with Betrán et al. (1).

The results revealed that there is non-significant relation between the number of previous CS and occurrence of UR. This was also approved by Lydon-Rochelle et al (20) study, they stated that the risk of uterus tearing open along the scar line from a prior CS (UR) is higher if a trial of normal labor is attempted after CS (TOLAC).

The study results revealed that there is non-significant relation between number of previous CS and occurrence of CSEP that agreed with Brancazio et al (21) study. They stated that the risk for CSEP does not necessarily increase with the number of CS. And also agreed with Jayaram et al (22)that stated that CSEP is a rare complication of pregnancy occurring in approximately 1 in 2000 pregnancies.

In contrast to study of Timor-Tritsch \& Monteagudo (4) who reported that CSEP is 
increasingly reported complication and its incidence is rising in parallel with the increased rate of repeated CS. This discrepancy may be due to the wide range duration of the study, unlike ours. Sensitivity of US in diagnosis of abnormal AFI equals $80 \%$ and accuracy equals $90.2 \%$. US alone is not adequate for evaluation of AFI specially at third trimester and when Oligohydramnios is suspected. This may be explained as at this time umbilical cord may seem extremely lucent as amniotic fluid and can be misdiagnosed as AF pocket. This agreed with Zlatnik et al (23) who showed the importance of the use of color Doppler to identify the umbilical cord in amniotic fluid.

The results disagreed with Magann et al (24) who stated in their study that the recent use of color Doppler sonography has not improved the diagnostic accuracy of sonographic estimates of the AFV but instead has led to over diagnosis of oligohydramnios.

Results showed that sensitivity of US in diagnosis of preterm labor is $75 \%$, and accuracy is $80.4 \%$, the decreased sensitivity of US in diagnosis of preterm labor may be accounted to the fact that the diagnosis of preterm fetus mostly depends on fetal growth in relation to menstrual GA which subsequently depends on fetal parameters and sonographic FBW that are highly affected by multiple factors including fetal factors as genetic (Long parents), pregnancy factors such as fetal sex, multiple pregnancy and AFV. Maternal factors as maternal diabetes. Technical factors such as Overestimation of the femur, and the fault calculation of the patient. This is agreed with Barel et al (25) stated that many maternal and fetal factors significantly influence the sonographic FBW and subsequent errors in calculation of GA and determination for timing of labor.

\section{Conclusion}

Pregnant females with prior CS are at risk of multiple complications that depend on the number of previous CS done including placental problems, IUGR, oligohydramnios, fetal malpositioning and preterm labor.

Problems of placenta are the most common complications related to the previous CS in the second trimester. The more CS patient have, the greater the risk of developing problems with the placenta such as the placenta implanting too deeply into the uterine wall (placenta accreta) or becomes partially or completely covering the opening of the cervix (P.P). 
US were a helpful modality that assisted in detection and evaluation of most of gestational problems during our study with accepted sensitivity and accuracy. So, it may be advised for the routine obstetric US examination for all patients known with previous CS.

\section{References}

1. tBetrán, A. P., Merialdi, M., Lauer, J. A., BingShun, W., Thomas, J., Van Look, P., et al (2007). Rates of caesarean section: analysis of global, regional and national estimates. Paediatric and perinatal epidemiology, 21(2), 98-113.

2. Gilliam, M. (2006). Cesarean delivery on request: reproductive consequences. Paper presented at the Seminars in Perinatology.

3. Rosen, T. (2008). Placenta accreta and cesarean scar pregnancy: overlooked costs of the rising cesarean section rate. Clinics in perinatology, 35(3), 519-529.

4. Timor-Tritsch, I. E., Monteagudo, A., Santos, R., Tsymbal, T., Pineda, G., \& Arslan, A. A. (2012). The diagnosis, treatment, and follow-up of cesarean scar pregnancy. American journal of obstetrics and gynecology, 207(1), 44. e41-44. e13.

5. Suhag, A., \& Berghella, V. (2013). Intrauterine growth restriction (IUGR): etiology and diagnosis. Current Obstetrics and Gynecology Reports, 2(2), 102-111.

6. Gonzalez, N., \& Tulandi, T. (2017). Cesarean scar pregnancy: a systematic review. Journal of Minimally Invasive Gynecology, 24(5), 731-738.
7. Maymon, R., Halperin, R., Mendlovic, S., Schneider, D., \& Herman, A. (2004). Ectopic pregnancies in a Caesarean scar: review of the medical approach to an iatrogenic complication. Hum Reprod Update, 10(6), 515-523. doi:10.1093/humupd/dmh042

8. Casey, B. M., McIntire, D. D., Bloom, S. L., Lucas, M. J., Santos, R., Twickler, D. M et al (2000). Pregnancy outcomes after antepartum diagnosis of oligohydramnios at or beyond 34 weeks' gestation. Am J Obstet Gynecol, 182(4), 909-912. doi:10.1016/s0002-9378(00)70345-0

9. Bricker, L., Neilson, J. P., \& Dowswell, T. (2008). Routine ultrasound in late pregnancy (after 24 weeks' gestation). Cochrane Database Syst $\quad \operatorname{Rev}(4), \quad$ CD001451. doi:10.1002/14651858.CD001451.pub3

10. Gjelsteen, A. C., Ching, B. H., Meyermann, M. W., Prager, D. A., Murphy, T. F., Berkey, B. D. et al (2008). CT, MRI, PET, PET/CT, and ultrasound in the evaluation of obstetric and gynecologic patients. Surgical Clinics of North America, 88(2), 361-390.

11.Kaur, A., \& Kaur, A. (2011). Transvaginal ultrasonography in first trimester of pregnancy and its comparison with transabdominal ultrasonography. Journal of Pharmacy and Bioallied Sciences, 3(3), 329.

12. Lazarus, E. (2003). What's new in first trimester ultrasound. Radiol Clin North Am, 41(4), 663679. doi:10.1016/s0033-8389(03)00039-3.

13. Rouse, C., Cantonwine, D. E., \& Shipp, T. D. (2019). Assessment of the Placental Cord Insertion Using 3-Dimensional Ultrasound at the Time of the Structural Fetal Survey. J Ultrasound Med, 38(7), 1791-1796. doi:10.1002/jum.14868 
14.Parvin, Z., Das, S., Naher, L., Sarkar, S. K., \&

Fatema, K. (2017). Relation of Placenta Praevia with Previous Lower Segment Caesarean Section (LUCS) in our Clinical Practice. Faridpur Medical College Journal, 12(2), 75-77.

15.Umbeli, T., Salah, I., Kunna, A., Rabaa, A., \& Mirghani, S. M. (2013). Association of placenta praevia with repeat cesarean section in Omdurman Maternity Hospital, Sudan 2010-2012. Sudan Journal of Medical Sciences, 8(4), 159162.

16.Kulas, T., Bursac, D., Zegarac, Z., PlaninicRados, G., \& Hrgovic, Z. (2013). New views on cesarean section, its possible complications and long-term consequences for children's health. Medical archives, 67(6), 460.

17. Rac MW, Dashe JS, Wells CE, Moschos E, McIntire DD \& Twickler DM. (2015). Ultrasound predictors of placental invasion: the Placenta Accreta Index. Am J Obstet Gynecol. 2015;212:343.e1-7.

18. Bano, S., Chaudhary, V., Pande, S., Mehta, V. L., \& Sharma, A. K. (2010). Color doppler evaluation of cerebral-umbilical pulsatility ratio and its usefulness in the diagnosis of intrauterine growth retardation and prediction of adverse perinatal outcome. The Indian journal of radiology \& imaging, 20(1), 20.

19. Oyinloye, O. I., \& Okoyomo, A. A. (2010). Longitudinal evaluation of foetal transverse lie using ultrasonography. African journal of reproductive health, 14(1).
20.Lydon-Rochelle, M., Holt, V. L., Easterling, T. R., \& Martin, D. P. (2001). Risk of uterine rupture during labor among women with a prior cesarean delivery. New England Journal of Medicine, 345(1), 3-8.

21. Brancazio, S., Saramago, I., Goodnight, W., \& McGinty, K. (2019). Cesarean scar ectopic pregnancy: Case report 27 . Radiology case reports, 14(3), 354-359.

22. ayaram, P. M., Okunoye, G. O., \& Konje, J. (2017). Caesarean scar ectopic pregnancy: diagnostic challenges and management options. The Obstetrician \& Gynaecologist, 19(1), 13-20.

\section{Zlatnik, M., Olson, G., Bukowski, R., \& Saade,} G. (2003). Amniotic fluid index measured with the aid of color flow Doppler. The Journal Of Maternal-Fetal \& Neonatal Medicine, 13(4), 242245.

24. Magann, E. F., Sandlin, A. T., \& Ounpraseuth, S. T. (2011). Amniotic fluid and the clinical relevance of the sonographically estimated amniotic fluid volume: oligohydramnios. Journal of Ultrasound in Medicine, 30(11), 1573-1585.

25. Barel, O., Maymon, R., Vaknin, Z., Tovbin, J., \& Smorgick, N. (2014). Sonographic fetal weight estimation-is there more to it than just fetal measurements? Prenatal diagnosis, 34(1), 50-55.

To cite this article: Hesham E. El sheikh, Shorouk Z. Abdelshafy, Hend F. El Welily. The Role of Ultrasound in Evaluation of Antenatal Complications Related to Previous Cesarean Section. BMFJ 2022; 39 (Radiology):78-88. DOI: 10.21608/bmfj.2021.50176.1346 